Original Research Paper

\title{
Sebaran Suhu Permukaan Laut (SPL) Secara Spasial dan Temporal di Perairan Selat Alas Provinsi Nusa Tenggara Barat
}

\author{
Didik Santoso ${ }^{1}$ * \\ ${ }^{1}$ Program Studi Pendidikan Biologi, Jurusan PMIPA FKIP Universitas Mataram
}

Article history

Received: 1 Januari 2019

Revised: 10 Januari 2019

Accepted: 8 Februari 2019

Published: 12 Februari 2019

*Corresponding Author:

\section{Didik Santoso,}

Program Studi Pendidikan Biologi Jurusan PMIPA FKIP

Universitas Mataram, Indonesia

Email:

didik_santoso@unram.ac.id
Abstract: Tujuan dari penelitian ini adalah unutk Menentukan sebaran suhu permukaan laut (SPL) secara spasial dan temporal di Selat Alas Provinsi NTB. Lokasi penelitian di wilayah perairan Selat Alas. Waktu penelitian selama 5 bulan yaitu dari bulan Agustus-Desember 2015. Data penelitian berupa data primer SPL Selat Alas dan data sekunder berupa data citra satelit Aqua MODIS Level-3 dengan resolusi spasial $0,05^{\circ} \times 0,05^{\circ}$ dan resolusi temporal 8 harian sebagai data bulanan yang cakupan waktunya dari Agustus 2008 sampai dengan Desember 2012. Data dianalisis dengan menggunakan algoritma Miami Pathfinder SST (MPFSST). Hasil penelitian menunjukkan bahwa secara spasial sebaran SPL Selat Alas didominasi oleh suhu rendah terutama yang berlokasi di bagian selatan, dan bagian tengah selat dengan suhu rata-rata sebesar $26.5^{\circ} \mathrm{C}$. Sedangkan secara temporal sebaran SPL wilayah perairan Selat Alas menunjukkan bahwa penurunan SPL terjadi disetiap bulan Agustus dan mulai meningkat pada bulan berikutnya, hingga mencapai suhu tertinggi pada bulan Desember, dan hal ini berulang setiap tahunnya. Suhu tinggi mendominasi seluruh bagian selat dengan suhu ratarata $29.5^{\circ} \mathrm{C}$ pada bulan November dan $29.0^{\circ} \mathrm{C}$ pada bulan Desember. Akan tetapi pada bulan Desember, pada bagian utara selat suhu rata-rata nya lebih tinggi dari daerah lainnya yaitu sebesar $29.7^{\circ} \mathrm{C}$.

Kata kunci: Citra Satelit , Selat Alas, Suhu Permukaan Laut, Spasial, Temporal

Abstract: The purpose of this study is to determine the spatial and temporal distribution of sea surface temperature (SST) in the Alas Strait of NTB Province. Research location in the Alas Strait waters. The research period is 5 months, from August to December 2015. The research data are in the form of primary data on the Alas Strait Sea Surface Temperature and secondary data in the form of Aqua satellite image MODIS Level-3, with spatial resolution of $0.05^{\circ} \times 0.05^{\circ}$ and 8 daily temporal resolutions, as monthly data from August 2008 to December 2012. Data were analyzed using the Miami Pathfinder SST algorithm (MPFSST). The results of the study indicate that spatially the distribution of Alas Strait Surface Temperature is dominated by low temperatures, especially those located in the south, and the central part of the strait with an average temperature of $26.5^{\circ} \mathrm{C}$. While temporally the distribution of Sea Surface Temperature in the Alas Strait waters region shows that the decline occurred every August and began to increase the following month, until it reached the highest temperature in December, and this recurs every year. High temperatures dominate the entire strait with an average temperature of $29.50 \mathrm{C}$ in November and $29.00 \mathrm{C}$ in December. However, in December, in the northern part of the strait the average temperature was higher than other regions, which amounted to $29.70 \mathrm{C}$.

Keywords: Satellite Imagery, Alas Strait, Sea Surface Temperature, Spatial, Temporal 


\section{Pendahuluan}

Selat Alas merupakan wilayah perairan laut yang memisahkan dua pulau utama di Provinsi Nusa Tenggara Barat (NTB). Dua pulau tersebut adalah Pulau Lombok di sebelah barat dan Pulau Sumbawa di sebelah timur. Karakteristik masa air di perairan Selat Alas ini dipengaruhi oleh fenomena lokal dan non-lokal. Sistem angin muson yang berubah arah sesuai musim merupakan fenomena lokal yang mengakibatkan variabilitas musiman dan tahunan (Wyrtki, 1961; Fieux et al., 1993; Clark et al., 1999). Fenomena non-lokal yang berinteraksi dengan sistem angin selain mempengaruhi variabilitas semi tahuan dan tahunan juga akan menimbulkan varibilitas antar tahunan.

Pada saat bertiup Angin Muson Tenggara (Juni - September) menyebabkan pergerakan massa air permukaan cenderung bergerak ke arah barat. Keadaan tersebut akan mempengaruhi karakteristik massa air karena pergerakan massa air dapat menyebabkan terjadinya pengangkatan massa air lapisan dalam pada wilayah tertentu dan pada akhirnya berdampak terhadap kesuburan suatu perairan. Pada saat bertiup Angin Muson Tenggara di wilayah ini poros Arus Katuliswa Selatan (AKS) bergeser ke dekat pantai Jawa - Sumbawa dan proses upwelling dapat terjadi sehingga lapisan permukaan tercampur lebih tipis dan suhunya menurun serta termokiln terangkat (Wyrtki, 1962; Purba, 2007).

Indikasi terjadinya upwelling disuatu perairan laut dapat dilihat dari sebaran suhu permukaan laut (SPL) secara spasial dan temporal. Sehingga dengan diketahuinya SPL maka dapat diduga suatu perairan laut terjadi upwelling sehingga dapat dikatakan bahwa perairan tersebut subur atau tidak. Daerah perairan yang subur dapat diindikasikan dengan kelimpahan fitoplankton yang tinggi serta konsentrasi klorofil-a yang tinggi pula. Fitoplankton berperan sebagai produsen primer dalam rantai kehidupan di laut, sehingga keberadaannya sangat penting sebagai dasar kehidupan di laut. Klorofil-a merupakan pigmen yang sangat penting dalam proses fotosintesis fitoplankton di laut (Strickland, 1960 dalam Nontji (1987).

Konsentrasi klorofil-a di suatu perairan dapat menggambarkan besarnya produktivitas primer di suatu perairan, karena klorofil-a hampir dimiliki oleh semua fitoplankton. Suhu dapat mempengaruhi fotosintesis di laut baik secara langsung maupun tidak langsung. Pengaruh suhu secara langsung yaitu dalam mengontrol reaksi kimia enzimatik pada proses fotosintesis fitoplankton, sehingga dapat menaikkan laju maksimum fotosintesis. Sedangkan pengaruh suhu secara tidak langsung yaitu dalam merubah struktur hidrologi kolom perairan yang dapat mempengaruhi distribusi dari fitoplankton (Tomascik et al. 1997). Selain itu, klorofil-a sangat berpengaruh dalam sistem rantai makanan di laut, karena dengan adanya kelimpahan klorofil-a di suatu perairan dapat menjadikan indikasi berkumpulnya ikan kecil yang merupakan jenis ikan herbifora untuk mencari makan dan disinilah rantai makanan itu terjadi.

Keberadaan klorofil-a di suatu perairan, sangat ditentukan oleh kondisi suhu perairan itu sendiri. Oleh karena itu keberadaan klorofil-a belum tentu merata di seluruh perairan, sekalipun perairan di sebuah selat. Penumpukan klorofil-a di lokasi tertentu dan sebaliknya kekosongan klorofila di lokasi lainnya, mengakibatkan kegiatan penangkapan juga terfokus di suatu perairan saja. Tujuan dari penelitian ini adalah unutk Menentukan sebaran suhu permukaan laut (SPL) secara spasial dan temporal di Selat Alas Provinsi NTB.

\section{Bahan dan Metode}

\section{Tempat dan Waktu Penelitian}

Penelitian ini dilakukan pada bulan Juli Desember 2015. Lokasi penelitian dilakukan di kawasan perairan Selat Alas Provinsi NTB (Gambar 1). 


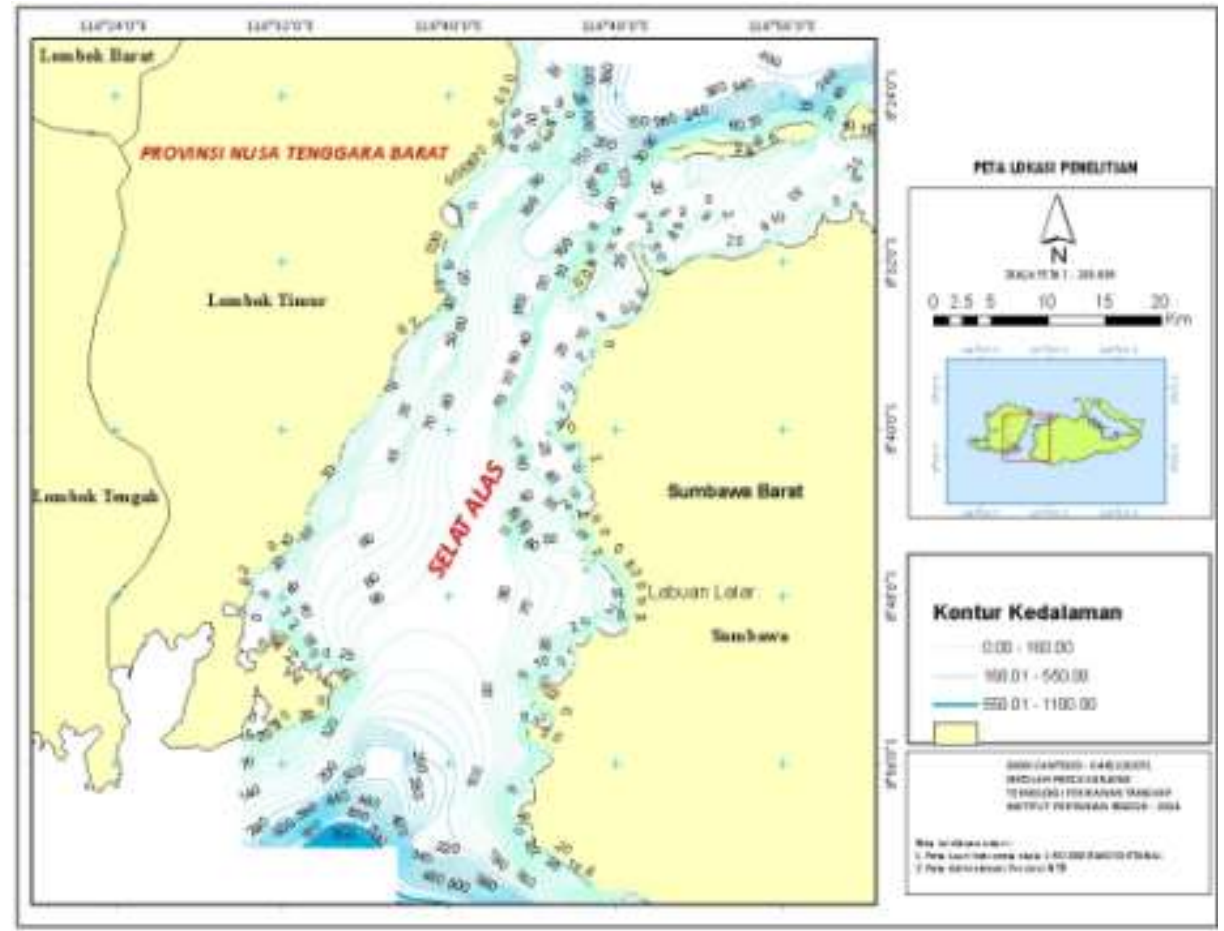

Gambar 1. Peta Lokasi Penelitian

\section{Pengumpulan Data Penelitian}

Jenis data yang digunakan adalah data primer dan data sekunder. Metode survai dilakukan untuk memperoleh data primer yaitu suhu permukaan laut yang diukur secara langsung.

Adapun data sekunder yang digunakan adalah data citra satelit Aqua MODIS Level-3 dengan resolusi spasial $0,05^{\circ} \times 0,05^{\circ}$ dan resolusi temporal 8 harian sebagai data bulanan yang cakupan waktunya dari Agustus 2008 sampai dengan Desember 2012. Data tersebut diperoleh dari Pacific Islands Fisheries Science Center(PIFSC) yang merupakan bagian dari National Oceanic and Atmospheric Administration (NOAA) - USA melalui laman website yang dikelolanya. Data citra ini digunakan untuk memperoleh informasi sebaran SPL di perairan Selat Alas Provinsi NTB. Data ini telah diformulasi untuk menghasilkan nilai pixel yang memuat kondisi SPL.

Selanjutnya data citra tersebut diolah dengan menggunakan perangkat lunak (software)
Ferret versi 6.85, kemudian hasil olahan tersebut menjadi input data pada software ArcGIS versi 9.1 sehingga didapatkan peta sebaran SPL secara spasial dan temporal. Data sekunder yang lain yaitu data arus permukaan air laut Selat Alas. Data arus permukaan air laut ini didapatkan dari ERDDAP (the Environmental Research Division's Data Access Program) yang juga merupakan bagian dari National Oceanic and Atmospheric Administration (NOAA) - USA melalui laman website : http: Ilcoastwatch.pfeg.noaa.gov/erddap/index.html.

\section{Analisis Data}

Suhu Permukaan Air Laut didapatkan dengan menggunakan algoritma Miami Pathfinder SST (MPFSST) (Minnett et al. 2002) dengan rumus :

$$
\begin{aligned}
\text { modis }_{s s t}= & c_{1}+c_{2} * T_{31}+c_{3} * T_{3132}+c_{4} * \\
& (\sec (\theta)-1) * T_{3132}
\end{aligned}
$$

Keterangan

$T_{31}=$ adalah brightness temperature (BT) pada band 31 (pada AVHRR kanal4) 
$T_{3132}=$ adalah perbedaan BT pada band 31-band 32 (pada AVHRR kanal 4 dan 5)

$c_{1}, c_{2}, c_{3}, c_{4}=$ adalah koefisien band 31 dan $32, \theta$ adalah sudut zenith satelit.

\section{Hasil dan Pembahasan}

Hasil pengolahan citra Aqua Modis terhadap Suhu Permukaan Laut di perairan Selat Alas secara temporal terlihat bahwa terjadi pola dan fluktuasi SPL bulanan rata - rata di Selat Alas. Sebaran SPL secara temporal di Selat Alas di dominasi oleh suhu rendah di bulan Agustus kemudian meningkat hingga bulan Desember. SPL rata-rata pada bulan Agustus mencapai $27.0^{\circ} \mathrm{C}$. Dominasi suhu rendah pada bulan Agustus ini terutama terjadi pada bagian selatan dan tengah Selat Alas, hal ini sebagai dampak dari rendahnya SPL di Samudera Hindia.

SPL tertinggi di selat alas terjadi pada bulan November hingga Desember dengan suhu rata-rata mencapai $29.8^{\circ} \mathrm{C}$. Dominasi suhu tinggi ini terjadi terutama pada bagian utara Selat Alas, dengan suhu rata-rata $28.6^{\circ} \mathrm{C}$. Peningkatan SPL pada bagian utara sebagai dampak dari tingginya SPL di Laut Flores (Gambar 2).

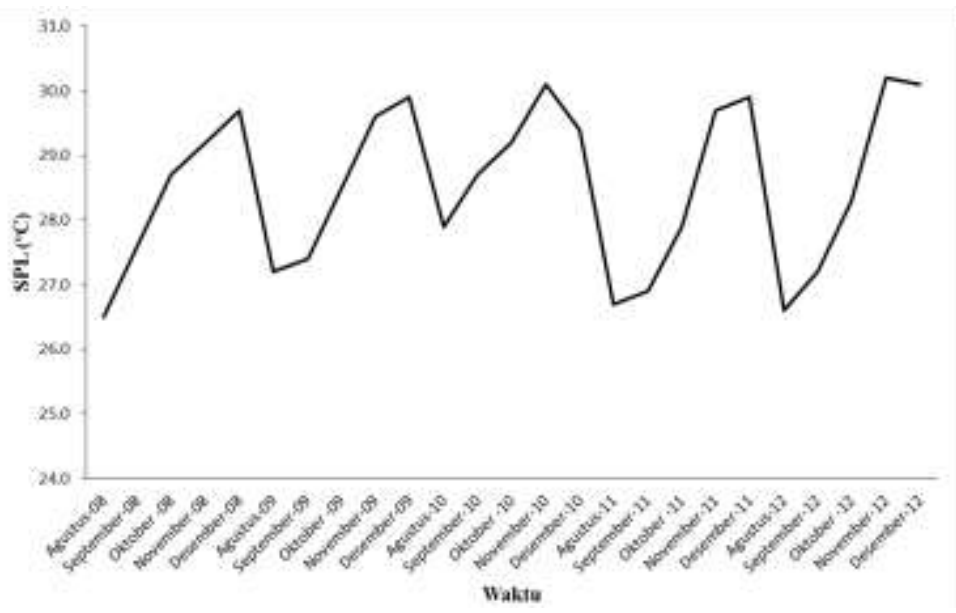

Gambar 2. Suhu rata-rata permukaan laut Selat Alas secara temporal (Agustus-Desember)

Gambar 2 juga menunjukkan bahwa penurunan SPL terjadi disetiap bulan Agustus dan mulai meningkat pada bulan berikutnya, hingga mencapai suhu tertinggi pada bulan Desember, dan hal ini berulang setiap tahunnya.

Secara spasial sebaran SPL Selat Alas tidak berbeda dengan sebaran secara temporalnya. SPL didominasi oleh suhu rendah terutama yang berlokasi di bagian selatan, dan bagian tengah selat dengan suhu rata-rata sebesar $26.5^{\circ} \mathrm{C}$. sedangkan bagian utara selat didominasi oleh suhu tinggi, dengan suhu rata-rata sebesar $28^{\circ} \mathrm{C}$. Sebaran SPL secara spasial pada wilayah perairan Selat Alas seperti di tunjukkan pada Gambar 3. 

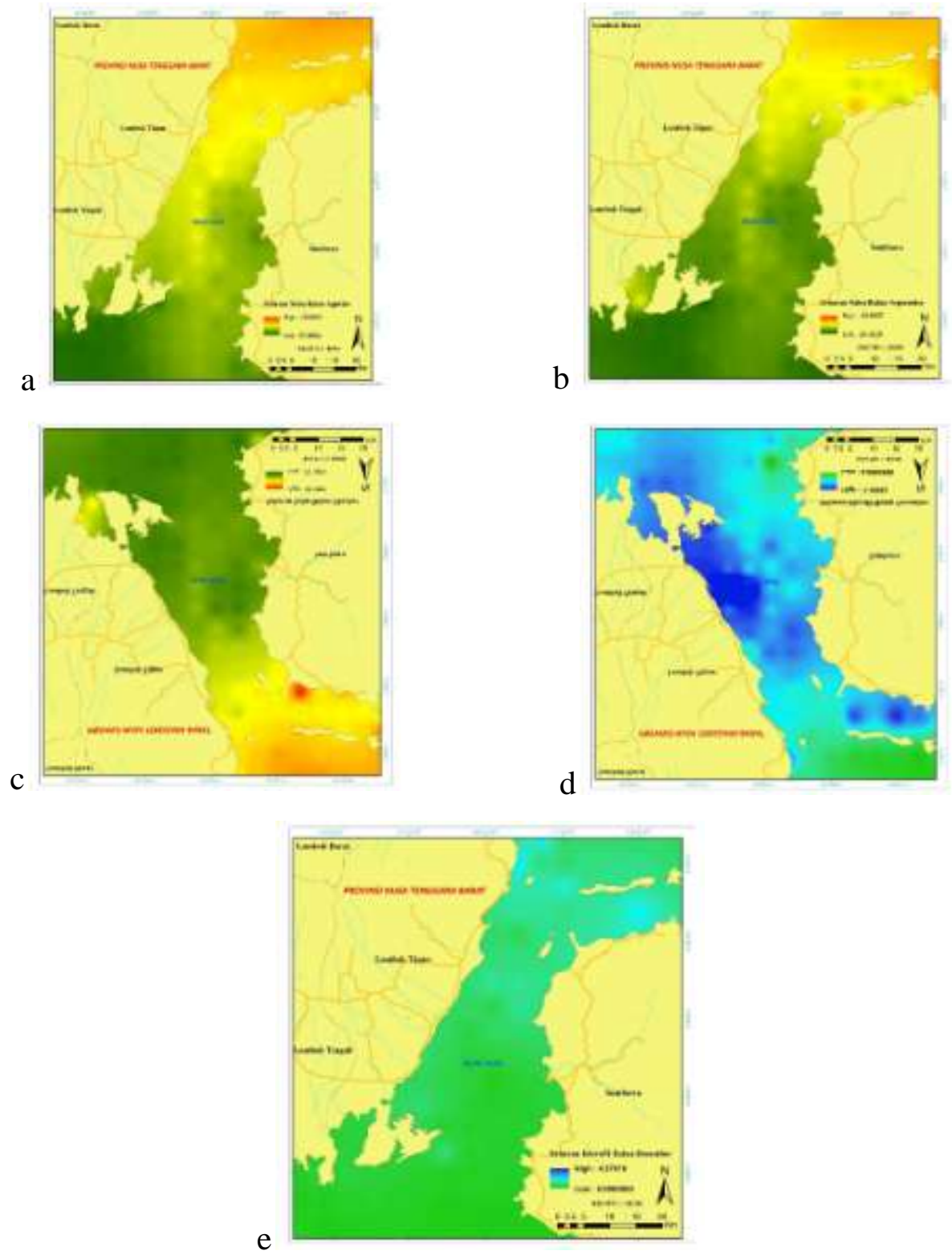

Gambar 3 Pola sebaran suhu perairan Selat Alas secara spasial periode bulan Agustus Desember ( a : Bulan Agustus, b: Bulan September, c : Bulan Oktober, d : Bulan November, e : Bulan Desember)

Error! Reference source not found.3 menunjukkan bahwa SPL rata-rata secara spasial Selat Alas terus meningkat secara gradual seiring waktu hingga mencapai puncaknya pada bulan November hingga Desember. Suhu tinggi mendominasi seluruh bagian selat dengan suhu rata-rata $29.5^{\circ} \mathrm{C}$ pada bulan November dan $29.0^{\circ} \mathrm{C}$ pada bulan Desember. Akan tetapi pada bulan
Desember, pada bagian utara selat suhu rata-rata nya lebih tinggi dari daerah lainnya yaitu sebesar $29.7^{0} \mathrm{C}$.

Penurunan SPL dibagian Selatan Selat Alas ada kaitannya dengan peristiwa upwelling di wilayah perairan Selatan Provinsi NTB. Pada bagian utara Selat alas didominasi oleh suhu tinggi dengan suhu rata-rata $28,6{ }^{\circ} \mathrm{C}$. Hal ini, sesuai 
dengan pernyataan Putra et al. (2014) yang menyatakan bahwa terjadi peningkatan SPL di Laut Jawa, Selat Makasar dan Laut Flores pada musim peralihan I (bulan Maret - Mei) dan II (bulan September - November) sedangkan pada bagian dalam selat dan pada daerah pantai di dominasi suhu rendah.

Rendahnya SPL pada bulan Agustus dan September terutama pada bagian selatan Selat Alas diakibatkan oleh angin Muson Tenggara (Juni September), hal ini seperti yang dinyatakan oleh Hidayat et al. (2013); Purba (2009) bahwa pada saat bertiup Angin Muson Tenggara (Juni September) poros Arus Katuliswa Selatan (AKS) bergeser ke dekat pantai Jawa - Sumbawa dan mengakbitkan SPL menurun. Sebaliknya pada saat Angin Musson Barat Daya bertiup (Desember Pebruari), poros AKS bergesar ke selatan dan Arus Pantai Jawa (APJ) mengalir ke timur (Wyrtki 1961). APJ membawa massa air yang lebih hangat, hal inilah yang mengakibatkan SPL di bagian selatan Selat Alas pada Bulan Desember menjadi lebih tinggi dari bulan-bulan yang lain (Sprintall et al., 2000). Pernyataan ini diperkuat dari hasil penelitian Kemili dan Putri (2012) bahwa di sepanjang pantai selatan Jawa Timur, Bali sampai Nusa Tenggara Timur memasuki bulan Juni sampai Agustus terlihat penurunan SST terus terjadi sehingga mencapai $>1.4 \mathrm{oC}$ dibawah rata-rata SST.

Nilai SPL rata-rata terendah terdapat pada bulan Agustus dan nilai rata-rata suhu permukaan laut tertinggi terdapat pada bulan Desember, hal ini sesuai dengan pernyataan yang dikemukakan oleh Kunarso et al. (2005) bahwa peristiwa upwelling yang terjadi di wilayah perairan Selatan Jawa hingga Timor sekitar bulan April hingga November. Mencapai intensitas upwelling optimum, pada periode Normal dan La Niña sekitar bulan Juli - September, puncaknya bulan Agustus, sedangkan pada saat El Niño puncaknya sekitar bulan September. Lebih jauh Kunarso et al. (2012) menyatakan bahwa secara umum kisaran suhu permukaan laut (SPL) di daerah upwelling di Selatan Jawa hingga Timor berkisar 26.18 - $28.35^{\circ} \mathrm{C}$ dengan rerata $27.04 \pm 0.93^{\circ} \mathrm{C}$. Mulai bulan Juni umumnya nilai suhu permukaan laut (SPL) semakin turun, kemudian berangsur normal kembali. Nilai suhu permukaan laut terendah ditemukan berkembang dari timur (Bali) pada bulan Juni bergerak ke barat hingga Jawa Barat. Berikutnya, Kunarso et al. (2012) menyatakan bahwa variabilitas SPL bulanan di daerah upwelling (selatan Jawa sampai Timor) pada bulan Juni ke Agustus cenderung mengalami penurunan. Hal ini diperkuat dengan hasil penelitian yang didapat oleh Saraswata et al. (2013) yang menyatakan bahwa nilai rata-rata suhu permukaan laut terendah di Selatan Bali adalah pada bulan Agustus, dengan nilai suhu rata-rata sebesar $27.08^{\circ} \mathrm{C}$.

Peristiwa upwelling yang terjadi di Selatan Jawa hingga selatan NTB ini juga dikemukakan oleh penelitian yang dilakukan oleh Setyono dan Harsono (2014) yang menyatakan bahwa terjadi penurunan SPL dan peningkatan konsentrasi klorofil-a pada bulan Juni - September yang diduga sebagai pengaruh adanya peristiwa upwelling sepanjang bulan tersebut. Raditya et al. (2013) menyatakan bahwa terjadi kondisi luasan upwelling meningkat pada bulan Juni hingga Oktober di sepanjang perairan pantai Selatan Jawa Timur hingga perairan selatan Lombok dengan kondisi paling luas terdapat pada bulan Agustus dan September diikuti dengan penurunan rata-rata suhu permukaan laut (SPL). Menurut Susanto et al. (2001), pada saat periode El Nino, wilayah upwelling di sepanjang pantai barat Sumatera hingga selatan Jawa meluas hingga mendekati ekuator dan berlangsung lebih lama hingga November dari biasanya hanya sampai bulan Oktober. Hal ini di perkuat oleh penelitian yang dilakukan oleh Kemili dan Putri (2012) yang menyatakan bahwa terjadi peningkatan produktivitas primer di wilayah perairan Selatan Jawa hingga Nusa Tenggara karena adanya proses upwelling pada saat musim timur (Juni - Agustsus).

Intensitas (kekuatan) upwelling yang dilihat dari tingkat penurunan temperatur permukaan laut 
(SPL) juga terlihat bervariasi di setiap wilayah dan waktu terjadinya. Tidak hanya menunjukkan durasi yang paling panjang, perairan selatan Jawa sampai Nusa Tenggara Timur (NTT) menunjukkan intensitas upwelling yang paling tinggi dibandingkan lokasi-lokasi lainnya di Indonesia dengan penurunan SST mencapai $2^{\circ} \mathrm{C}$ di bawah SPL rata-rata saat musim timur (tahun-tahun normal) (Kemili dan Putri 2012).

Karakteristik massa air Selat Alas juga dipengaruhi oleh Indian Ocean Dipole Mode (IODM). Fenomena Indian Ocean Dipole Mode (IODM) yang terjadi di Samudera Hindia tropis mempengaruhi variabilitas karakter massa air di wilayah in. Saat terjadi IODM positif yang berkaitan dengan pendinginan suhu permukaan laut dan pendangkalan lapisan termoklin serta menguatnya intensitas upwelling di bagian timur Samudera Hindia di mana pengaruh fenomena ini dapat juga mencapai selatan Jawa - Sumbawa (Saji dan Yamagata, 2003).

\section{Kesimpulan}

Secara spasial sebaran SPL Selat Alas didominasi oleh suhu rendah terutama yang berlokasi di bagian selatan, dan bagian tengah selat dengan suhu rata-rata sebesar $26.5^{\circ} \mathrm{C}$. Sedangkan secara temporal sebaran SPL wilayah perairan Selat Alas menunjukkan bahwa penurunan SPL terjadi disetiap bulan Agustus dan mulai meningkat pada bulan berikutnya, hingga mencapai suhu tertinggi pada bulan Desember, dan hal ini berulang setiap tahunnya. Suhu tinggi mendominasi seluruh bagian selat dengan suhu rata-rata $29.5^{\circ} \mathrm{C}$ pada bulan November dan $29.0^{\circ} \mathrm{C}$ pada bulan Desember. Akan tetapi pada bulan Desember, pada bagian utara selat suhu rata-rata nya lebih tinggi dari daerah lainnya yaitu sebesar $29.7^{\circ} \mathrm{C}$.

\section{Daftar Pustaka}

Clark, Christina Oelfke, Julia E. Cole, Peter J. \& Webster (2000). Indian Ocean SST and
Indian Summer Rainfall: Predictive Relationships and Their Decadal Variability. J. Climate, 13: 2503-2519

Hidayat, S., Purba, M. \& Waworuntu J. (2013). Variabilitas Suhu Di Perairan Senunu, Sumbawa Barat. Jurnal Ilmu dan Teknologi Kelautan Tropis 5(2): 243-259.

Fieux, M., C. Andrie, P. Delecluse, A.G. Illahude, A. Kartavtseef, F. Mantisi, R. Molcard, \& J.Swallow. (1993). Measurements within the Pacific-Indian Ocean Throughflow Region. Deep-Sea research I, 41(7):1091-1130.

Kemili, P. \& Putri, M.R. (2012). Influences Of Upwelling Duration And Intensity Based On Sea Surface Temperature Anomaly Toward Primary Productivity Variability In Indonesian Waters. Jurnal Ilmu dan Teknologi Kelautan Tropis 4(1).

Kunarso, K., Hadi, S. \& Ningsih, NS. (2005). Kajian Lokasi Upwelling untuk Penentuan Fishing Ground Potensial Ikan Tuna. ILMU KELAUTAN: Indonesian Journal of Marine Sciences 10(2): 61-67.

Kunarso K, Hadi S, Ningsih NS, \& Baskoro MS. (2012). Variabilitas Suhu dan Klorofil-a di Daerah Upwelling pada Variasi Kejadian ENSO dan IOD di Perairan Selatan Jawa sampai Timor. Ilmu Kelautan: Indonesian Journal of Marine Sciences 16(3): 171-180.

Minnett, P., Evans, R., Kearns, E. \& Brown, O. (2002). Sea-surface temperature measured by the Moderate Resolution Imaging Spectroradiometer (MODIS). Geoscience and Remote Sensing Symposium, 2002. IGARSS'02. 2002 IEEE International, IEEE.

Nontji, A. (1987). Laut nusantara. Jakarta (ID): Djambatan. 
Putra, E., Gaol, JL. \& Siregar, VP. (2014). Relationship Chlorophyll-a Concentration And Sea Surface Temperature With Primary Pelagic Fish Cathes In Java Sea From MODIS Satellite Images. Jurnal Teknologi Perikanan Dan Kelautan 3(1):1-10.

Purba, M. (2009). Dynamics of south JavaSumbawa waters during south east monsoon. International Symposium of Marine Science, Technology and Policy. World Ocean Conference. Manado, 12-14 Mei 2009.

Raditya, FD., Ismunarti, DH. \& Handoyo, G. (2013). Analisis Prakiraan Luasan Daerah Upwelling di Perairan Selatan Jawa Timur Hingga Selatan Lombok Kaitannya Dengan Hasil Perikanan Tangkap. Journal of Oceanography 2(1): 111-127.

Saji, N. \& Yamagata, T. (2003). Possible impacts of Indian Ocean dipole mode events on global climate. Climate Research 25(2): 151169.

Saraswata, AG., Subardjo, P. \& Muslim, M. (2013). Pengaruh Monsun Terhadap Distribusi Suhu Permukaan Laut Dan Klorofil-A Di Perairan Selatan Bali. Journal of Oceanography 2(1): 79-87.

Setyono, H. \& Harsono, G. (2014). Dinamika Upwelling Dan Downwelling Berdasarkan Variabilitas Suhu Permukaan Laut Dan Klorofil-a Di Perairan Selatan Jawa. Journal of Oceanography 3(1): 57-66.

Sprintall, J., Gordon, AL., Murtugudde, R. \& Susanto, RD. (2000). A semiannual Indian Ocean forced Kelvin wave observed in the Indonesian seas in May 1997. Journal of Geophysical Research: Oceans (1978-2012) 105(7): 17217-17230.
Tomascik, T., Mah, A., Nontji, A. \& Moosa, M. (1997). The ecology of Indonesia series volume III part one: the ecology of Indonesian Seas. Singapore (SN): Periplus Editions (HK) Ltd., 642p.

Wyrtki, K. (1962). The upwelling in the region between Java and Australia during the southeast Monsoon. Aust. J. Mar. Freshwater Res.17:217-225. 